\title{
Analysis of the Current-Voltage Characteristic during the Corona Discharge in Wires-To-Planes Electrostatic Precipitator under Variable Air Humidity
}

\author{
H. Ait SAID ${ }^{a, b, *}$, M. Aissou ${ }^{a}$, H. Nouri ${ }^{a}$ AND Y. ZeBbOUdJ ${ }^{a}$ \\ ${ }^{a}$ Laboratoire de Génie Electrique, Université A. Mira de Bejaïa, 06000 Bejaïa, Algeria \\ ${ }^{b}$ Département de Génie Electrique, Institut des Sciences et de la Technologie, \\ Centre Universitaire A-Zabana de Relizane, 48000 Relizane, Algeria
}

(Received March 20, 2017; in final form February 4, 2019)

\begin{abstract}
In the present work an experimental investigation has been carried out on the influence of the air humidity or the water vapor injected in the incoming air flow on DC corona discharge parameters in a wire-to-planes electrostatic precipitators. To characterize the behavior of the corona discharge for both positive and negative corona, the current-voltage characteristics are subjected to an analysis using the model of Cooperman which derives the quadratic Townsend law and the general formula proposed by Meng et al. The experimental results show that the discharge current is strongly influenced by the level of air humidity. Moreover, the corona current becomes very small with the applied voltage beyond $H_{r}=90 \%$, because the particle size is increased by condensation. It was demonstrated that the Coopeman model is reliable to determine the mobility of the charge carriers in this system.
\end{abstract}

DOI: 10.12693/APhysPolA.135.320

PACS/topics: air humidity, corona discharge, electrostatic precipitators, current-voltage, mobility

\section{Introduction}

The corona discharge is used in a wide variety of electrostatic processes such as electrostatic precipitation in plants [1], spraying powders, the production of electrets, separating granular compounds, electro- photographic printing [2], the production of ozone and the decomposition of toxic gas [3]. Industrial electrostatic precipitators (ESPs) have an important role in maintaining a clean environment and improve the quality of ambient air.

The originality of the positive or negative corona discharge is the presence of an ionization region near the active wires where the charges are produced by electronics collisions due to the intense electric field and a drift region of ions near the grounded planes where the electric field is lower $[4,5]$. In the case of a positive discharge, positive ions migrate through the inter-electrode space. With the negative discharge, positive ions return quickly to the cathode, while electrons and negative ions formed by electron attachment migrate into the drift region.

The ESPs system consists of one or more wires submitted to high voltage and one or more collecting electrodes usually grounded $[6,7]$. The dusting is performed by electric forces acting on the charged particles and the corona discharge in the gas mixture provides the energy

*corresponding author; e-mail: hakimdoz@yahoo.fr needed to decompose the pollutant. The ions produced by the corona discharge are used for charging the dust particles to direct them to a collecting electrodes $[8,9]$. The concept for an airborne particle collector, capable of capturing efficiently and independently of size, any kind of aerosol ranging from a few tens of nanometers to a few micrometers $[10,11]$. The collection device consists in a standard electrostatic precipitator, where the particle are charged via an electrical corona discharge and collected subsequently due to the electrostatic forces [12]. In addition, a small amount of water vapor is injected in the incoming air flow improving greatly the yield for the collection of nanoscale particles $[13,14]$. This method has the valuable advantage of having a very good yield for a wide range of particle size $(20 \mathrm{~nm}$ to $2 \mu \mathrm{m})[9,13]$. Otherwise, the humidity modifies the corona behaviour due to the electronegative nature of water vapor; adding water vapor to air would increase the attachment coefficient of the mixture. However, the basic principle of wet ESP is identical to the dry ESP, the difference lies in the presence of a layer of damp on the collecting electrodes and besides the interelectrode air is saturated with water vapor [15-17].

The corona discharge is typically characterized by a quadratic relationship between the current and voltage. The general $I-V$ dependence for corona discharge is given by Townsend's law for the case of wire-to-cylinder configuration [18, 19]:

$$
\begin{aligned}
& I=K V\left(V-V_{0}\right), \\
& I / V=K\left(V-V_{0}\right),
\end{aligned}
$$$$
\text { or }
$$ 
where $I$ is the corona current, $V$ - the applied corona voltage, $V_{0}$ - the corona threshold voltage and $K$ a dimensional constant depending on the outer cylinder radius $R$, the wire electrode radius $r_{0}$ and the charge carriers mobility in the drift region $\mu$.

Other authors have reported attempts to derive the Townsend law for the point-to-plane [20] and wire-toplane system [21]. The topical research on the corona current-voltage characteristic has reported attempts to elaborate a model for the Townsend law where the dimension of the active electrode radius and the air gap are associated.

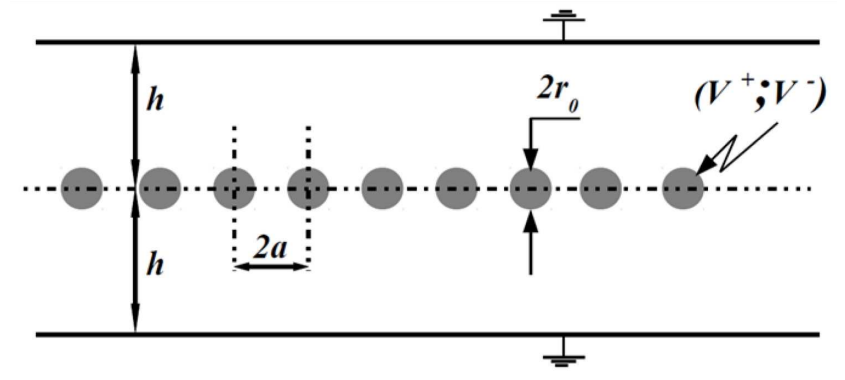

Fig. 1. Cross-section of a duct precipitator.

The configuration wires-to-two planes, as indicated in Fig. 1, is particularly used for the ESPs. This configuration is subject to many theoretical and experimental studies. Cooperman [22-24] was one of the pioneers who established the law for the corona inception in ESPs. He gives the current-voltage law, identical to the Townsend law, under the following form:

$$
I / V=K\left(V-V_{0}\right),
$$

where

$$
K=\frac{4 \pi \varepsilon_{0} \mu}{h^{2} \log \left(\frac{d}{r_{0}}\right)}
$$

and the equivalent cylinder radius $d$ is given by

$$
\begin{aligned}
& \text { for } \frac{h}{a} \leq 0.6, \quad d=\frac{4 h}{\pi}, \\
& \text { for } \frac{h}{a} \geq 2.0, \quad d=\frac{a}{\pi} \mathrm{e}^{\frac{\pi h}{2 a}},
\end{aligned}
$$

where $h$ is the wires-to-plane spacing, $a$ is the half wireto-wire spacing and $r_{0}$ is the wire radius. Some effect of humidity on DC corona are not well known in ESPs and requires further investigations and the main objective of our investigation is to study this effect on positive and negative corona discharge behavior in wire-to-plane configuration of the ESPs. An experimental method on the current-voltage measurements with varying humidity of the ambient air, free of particles, is carried out. The relative humidity can vary from $50 \%$ up to saturated conditions, on both positive and negative DC corona discharge employed in wire-to-plane ESPs. In particular, currentvoltage characteristics and ionic mobility are analyzed and discussed.

\section{Experimental apparatus and methods}

The experimental method developed in this paper aims to obtain new measurements of current-voltage characteristics for both positive and negative DC corona discharge in wire-to-plane ESPs and in which the humidity of ambient air, free of particles, is controlled. As shown in Fig. 2, 9 parallel nickel wires (1), with $2 R=0.4 \mathrm{~mm}$ diameter, are fixed with two insulating supports (2) and located midway between two planes (E) and (C) at $h=50 \mathrm{~mm}$ and the wire-to-wire spacing is fixed at $2 a=40 \mathrm{~mm}$. the ratio $h / a=2.5$ and the equivalent radius of the experimented wire-to-plane ESP according to the Eq. (6) is thus $d=323 \mathrm{~mm}$. The two planes and the two guard planes $(\mathrm{G})$ are made of stainless steel, their width is $l=200 \mathrm{~mm}$ and their length is $L=800 \mathrm{~mm}$. The plane of measurements (E) is connected to ground via a current signal resistance $R_{m}$ and the guard planes $(\mathrm{G})$ are directly connected to ground. The planes are fixed with insulating props (3), (5) and the leakage current between hight voltage wires and the plane $(\mathrm{E})$ of measurements is evacuated to earth by guard planes $(\mathrm{G})$ and reinforced with the stainless plate (4). An $0.5 \mathrm{~mm}$ air gap between the plane (E) and the guard planes $(\mathrm{G})$ is necessary in order to obtain the continuity of current and field distributions at the ends of $(\mathrm{E})$.

A DC voltage $V$, supplied by 0 to $\pm 140 \mathrm{kV}$ source (6), is applied to the corona wires and a high voltage divider (8) and a DC digital voltmeter (7) are used to measure
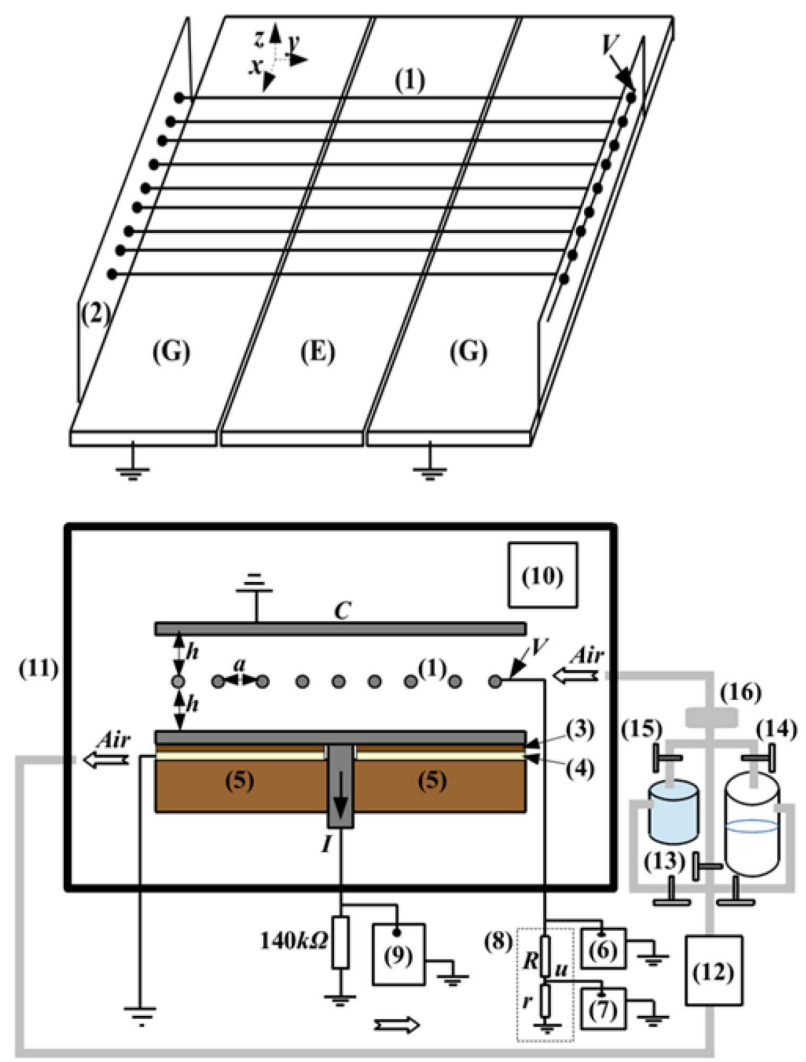

Fig. 2. Experimental setup. 
the applied voltage. The corona current measurement is achieved by the measurement of the potential drop across the resistance $R m$ with the DC digital voltmeter (9).

The wires-to-planes ESPs and the measurement devices of temperature (10) and humidity (11) are placed into a box of of about $200 \mathrm{l}$ and the measurement devices of the corona voltage and the corona current are placed out off the box in order to avoid the influence of the humidity. Air inside this box comes from the ambient atmosphere and made in closed circulation with a pump (12). The humidity is controlled with a three ways circuit with taps. Air is hydrated (14) with the water vapour provided by heating a half full bottle of distilled water; ways (13) and (15) being closed. The drying of the air is made by the way (16) in using silicagel contained in a bottle, when the ways (14) and (13) are closed. The opening of way (13), the closing of ways (14) and (15) of the circuit allow to keep a constant humidity inside the box. Air is then filtered (16) before it is let again in the box. In order to eliminate the possible influence of the air flow on the corona discharge, the pump is stopped during the measurements.

A digital video camera is used to register simultaneously the indications of the two digital voltmeters (7) and (9) used for the measurements respectively for the applied potential and the corona current. The applied potential $V$ is raised gradually from the value $V_{1}$ to the value $V_{2}$ such as $V_{1}<V_{0}<V_{2}$, where $V_{0}$ is the corona threshold voltage. The playback of the video recording can easily restore the values of corona current and the applied potential in order to draw the currentvoltage characteristics. This procedure of direct record of the current-voltage characteristics has several advantages. The stability of the corona discharge test gap can be quickly verified from the reproducibility of the characteristic.

\section{Results as function of the relative humidity}

The present work is concerned with the measurements of the corona current-voltage characteristics for both positive and negative polarity of the applied corona voltage. The distance between the wires is fixed to $a=$ $40 \mathrm{~mm}$ and the wire height is $h=50 \mathrm{~mm}$ and the tests are done in a large range of the corona voltage with varying humidity levels. The temperature and the pressure inside the box remain practically constant during the tests.

\subsection{Current-voltage characteristics}

The measured current-voltage characteristics in various relative humidity follow the quadratic Townsend law as shown in Figs. 3 and 4 . The current increases progressively with the applied voltage when it exceeds a certain threshold value $V_{0}$, and up to the breakdown tension. The DC current through the inter-electrode gap is a nonlinear function of the applied voltage. The presence of humidity $\mathrm{Hr}$ in air gap modifies the $I-V$ characteristics. At a given applied voltage when $H r$ increases, the corona current decreases significantly.

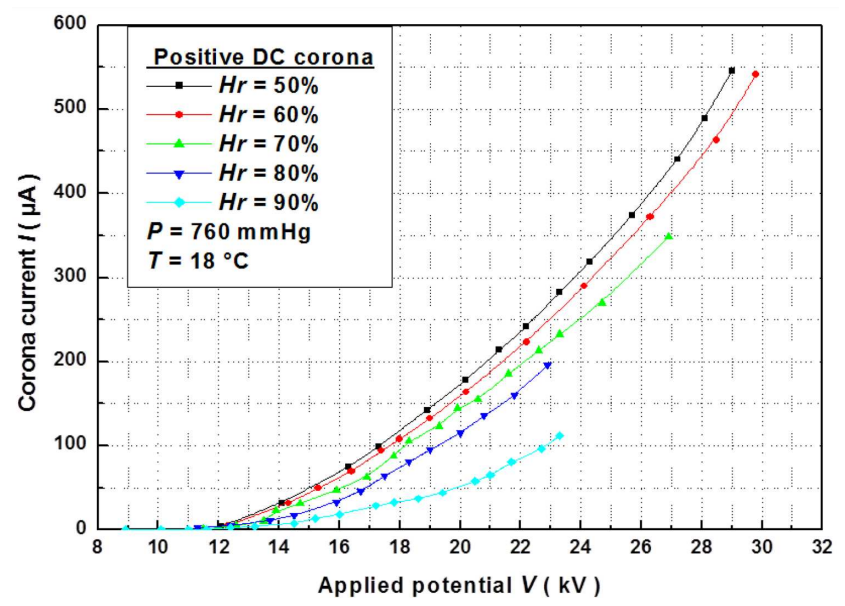

Fig. 3. Measured current-voltage characteristics for the positive $\mathrm{DC}$ corona in various relative humidity.

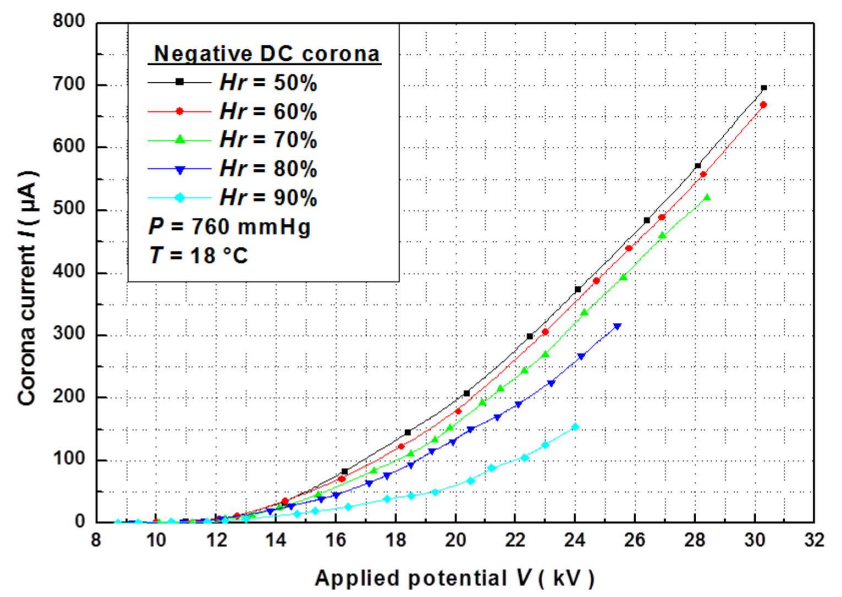

Fig. 4. As in Fig. 3, but for the negative DC corona.

The measured $I-V$ characteristics of the negative DC corona are always upper to those measured with the positive one, Fig. 5. The negative values of current are higher than the positive ones for the same applied voltage and the same humidity level.

Whatsoever the humidity value, the time evolution of the discharge current presents a strong pulse component. These Trichel pulses are very short and quite regular [25]. As predicted, the frequency of the pulses increases with increasing the time-averaged current. The humidity clearly affects the current pulse magnitude and duration. In fact, they become intense and shorter with increasing humidity, which means that a big amount of charge carriers are collected on the electrodes during a very short time following the Trichel pulse ignition. This can be explained by a narrow distribution of the apparent mobility at high humidity. The humidity can change the discharge regime.

The measured current/voltage ratio $I / V$ as a function of $\left(V-V_{0}\right)$ is linear as shown in Fig. 6a and b for both DC positive and negative corona. Thus the corona threshold voltage $V_{0}$ can be defined from the intersection of the 


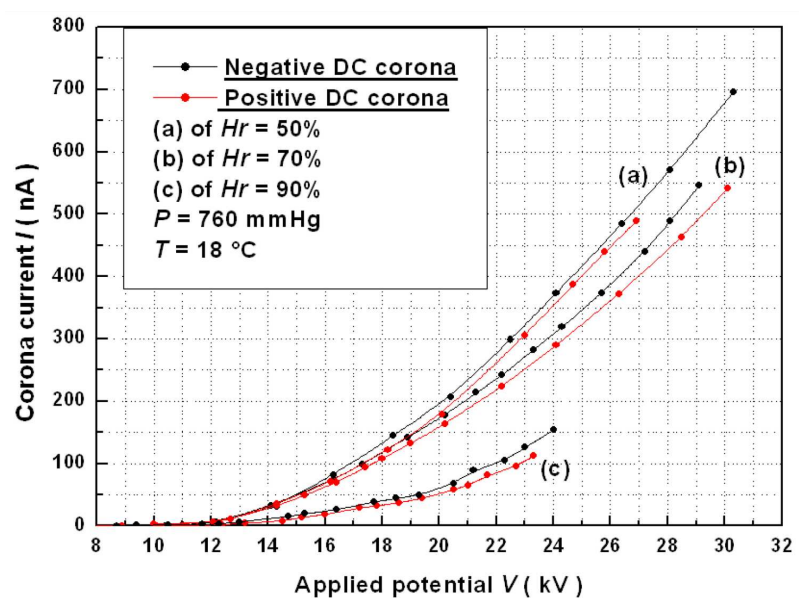

Fig. 5. Comparison of the current-voltage characteristics for the positive and negative corona.
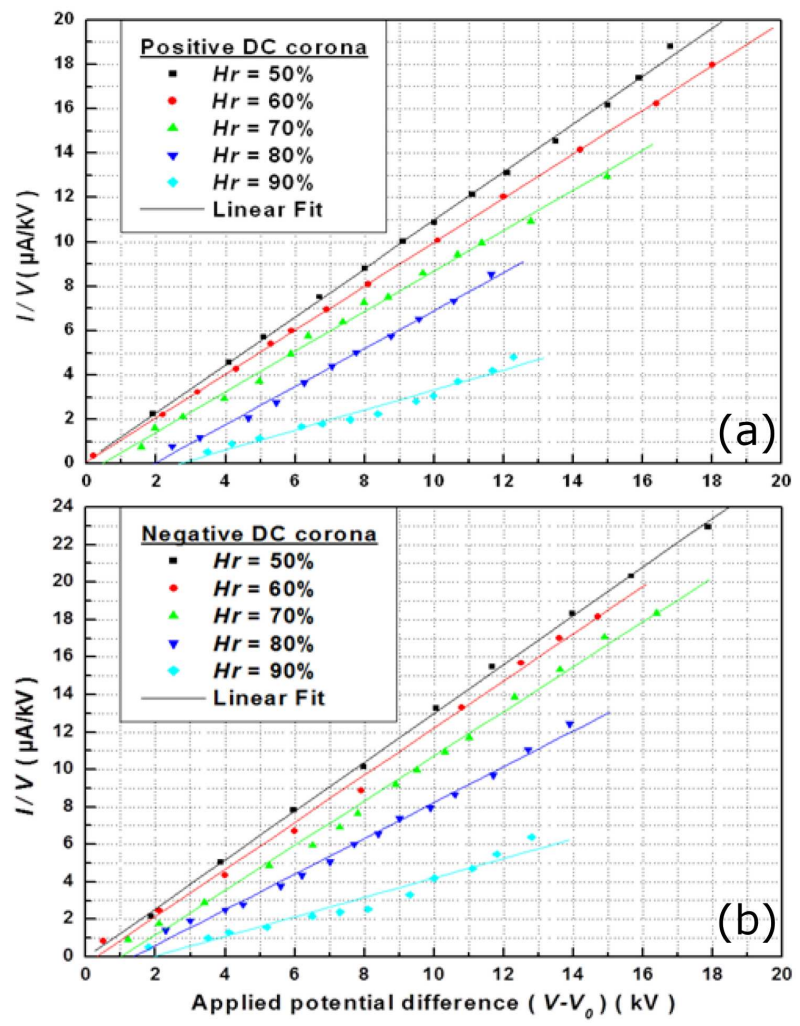

Fig. 6. The dependence of the positive (a), negative (b) current/voltage ratio $(I / V)$ on the voltage difference $\left(V-V_{0}\right)$.

characteristic with the voltage axis. The geometric factor $K$ which depends on the charge carriers mobility $\mu$ is the slope of the characteristic. The value of $\mu$ is not wellknown and we can find in the literature values between $1.1 \times 10^{-4} \mathrm{~m}^{2} /(\mathrm{V} \mathrm{s})$ and $4 \times 10^{-4} \mathrm{~m}^{2} /(\mathrm{V} \mathrm{s})$ [26-29]. These discrepancies can result from the model used for mobility calculation and the unknown experiment conditions such as the pressure, the humidity and not filtered ambient air. The value of the charge carriers mobility $\mu$ is taken as

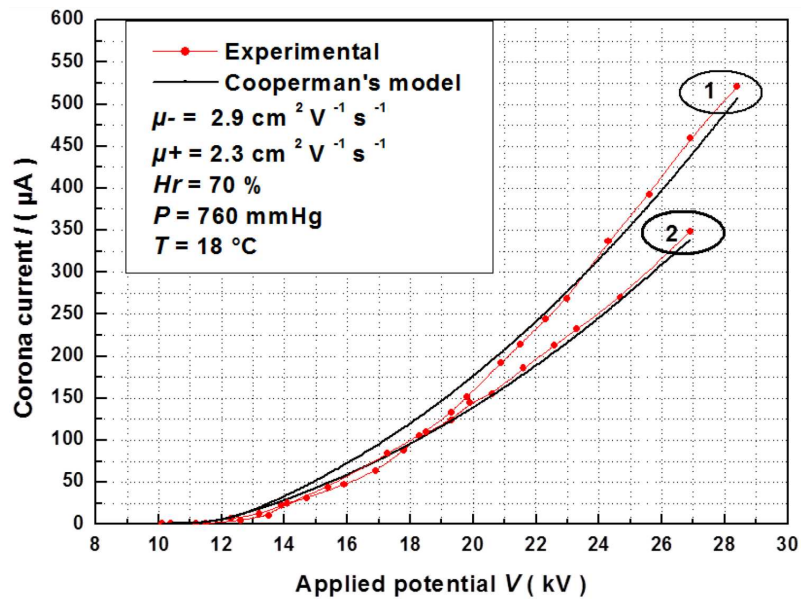

Fig. 7. Current-voltage characteristics of Cooperman's model and experimental results: 1 - negative DC corona, 2 - positive DC corona.

constant in the drift region. In the model of Cooperman the value of $\mu_{+}$is taken equal to $2.3 \times 10^{-4} \mathrm{~m}^{2} /(\mathrm{V} \mathrm{s})$ for the positive corona and for the negative corona equal to $\mu_{-}=2.9 \times 10^{-4} \mathrm{~m}^{2} /(\mathrm{V} \mathrm{s})$. We have obtained the value of the corona onset voltage $V_{0}$ equal to $11.5 \mathrm{kV}$ for positive corona and $V_{0}=11.8 \mathrm{kV}$ for negative corona.

As shown in Fig. 7, we remark that the model for the Townsend law introduced by Cooperman in Eqs. (3), (4), and (6) agrees well with the experimental measurements for both positive and negative DC corona. Historically, experiments have generally followed the form suggested by the classical Townsend law for the current-voltage characteristic. However, it should be noted that others have suggested alternative relationships given in [30-33]. The mathematical processing of the experimental data and the application of the updated knowledge of the corona threshold has allowed to modify the Townsend law as described by Meng et al. A new general formula in characterizing the relationship of the corona currentvoltage was derived and expressed as

$$
I=A\left(V-V_{0}\right)^{n} \text {. }
$$

This equation can also be written as

$$
\log _{10}(I)=n \log _{10}\left(V-V_{0}\right)+b,
$$
with $A=10^{b}$.

The $I-V$ characteristics of the wires-to-planes system appear also to follow the general formulae proposed by Meng et al. [20] given by Eq. (7) where the parameter $n$ can be determined by Eq. (8) and shown in Fig. 8a and b for both DC positive and negative corona. The influence of humidity on the values of the parameter $n$ is shown in Table I. We note that the value of $n \approx 1.5$ for low humidity and $n \approx 2.0$ for high humidity. Furthermore, it was demonstrated that the formula is applicable not only for both negative and positive coronas in point-to-plane geometries but also for both polarities in wires-to-planes geometries. With the optimal exponent $n$, the formula can well explain the inconsistencies met by other existing 

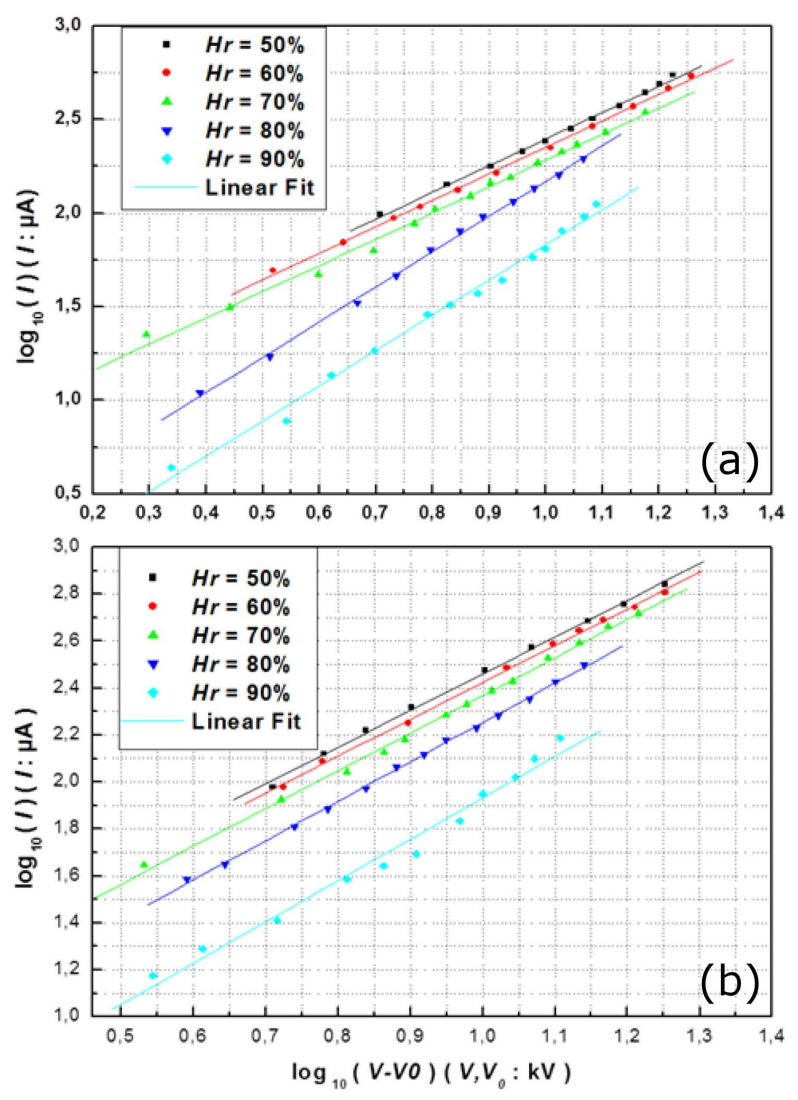

Fig. 8. The dependence of the positive (a), negative (b) current $I$ on the voltage difference $\left(V-V_{0}\right)$ on a $\log$ scale.

TABLE I

Results of exponent $n$ with different humidity value.

\begin{tabular}{c|c|c|c|c|c}
\hline \hline \multirow{2}{*}{ Exponent $n$} & \multicolumn{5}{|c}{ Air humidity $\mathrm{Hr}[\%]$} \\
\cline { 2 - 6 } & 50 & 60 & 70 & 80 & 90 \\
\hline positive DC corona & 1.57 & 1.52 & 1.53 & 1.66 & 1.80 \\
negative DC corona & 1.54 & 1.57 & 1.61 & 1.68 & 1.76 \\
\hline$P=760 \mathrm{mmHg}$ and $T=18^{\circ} \mathrm{C}$
\end{tabular}

formulae and best represent the characteristics of corona current-voltage with a good accuracy. Consequently, its significance exists not only in the practice but also in the scientific interest of corona discharges. Potentially, this formula may provide a clue for more sophisticated studies of corona phenomena.

\subsection{Average charge carriers mobility}

Various authors found an average mobility which decreases when the air humidity increases. In addition, Zebboudj et al. [8] have shown that the mobility depends on the potential difference across the drift region.

The Cooperman model for the wire-to-planes of ESPs is interesting, because the measurement of the geometric factor $K$ can determine the ionic mobility in using Eqs. (4) and (6):

$$
\mu=\frac{K h^{2} \log \left(\frac{d}{r_{0}}\right)}{4 \pi \varepsilon_{0}} .
$$

The variations of $\mu$ with $H r$ are shown in Fig. 9 for both positive and negative DC corona. The mobility decreases significantly when the relative humidity increases. The values of the negative mobility $\mu_{-}$are higher than the positive mobility $\mu_{+}$at a given relative humidity. This is due to the difference in apparent mobility of the charge carriers. Indeed, in negative polarity, significant part of the charge carriers in the drift region are electrons whose mobility is much higher than those of positive and negative ions.

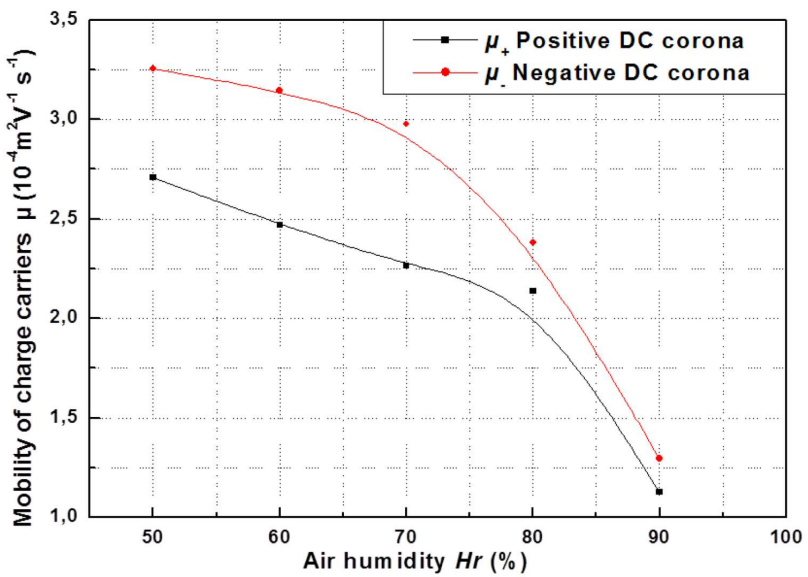

Fig. 9. Variation of the charge carriers mobility with the relative humidity.

\section{Conclusion}

In this paper, the measurements carried out show that the corona current shows a square-law variation with the applied potential. The Cooperman model for the wire-toplanes system is used to analyse the current-voltage characteristic and the mobility of the charge carriers. This characteristic is strongly modified by the relative humidity of the ambient air.

We have shown that the Cooperman model, for the wire-to-plane ESPs, which indicates that the wires-totwo planes system is equivalent to a coaxial system, is valid. The agreement between values obtained with this model and those obtained experimentally is satisfactory, in particularly for the negative DC corona.

Both the corona current and the mobility of the charge carriers are significantly reduced by increasing the relative humidity. We show also that the negative mobility is always higher than the positive mobility and this is due to the contribution of the electron part in the drift region.

Based on the experimental data and the knowledge of corona onset, a new general formula developed by Meng et al. for uncover the phenomena in point-to-plane geometry corona discharges can also be applied in wiresto-planes system of electrostatic precipitators where the exponent $n$ is in the range 1.5 to 2.0 . 


\section{References}

[1] I. Yamamoto, H.R. Velkoff, J. Fluid Mech. 108, 1 (1981).

[2] L.B. Schein, Electrophotography and Development Physics, Springer, Berlin 1989.

[3] J.S. Chang, P.A. Lawless, T. Yamamoto, IEEE Trans. Plasma Sci. 19, 191152 (1991).

[4] H. Nouri, M. Aissou, H. Ait Said, Y. Zebboudj, Int. J. Numer. Model. 28, 138 (2015).

[5] H. Nouri, H. Ait Said, Y. Zebboudj, N. Zouzou, L. Dascalescu, IEEE Trans. Diel. Electr. Insulat. 23, 665 (2016).

[6] H. Ait Said, H. Nouri, Y. Zebboudj, J. Electrost. 73 19 (2015)

[7] H. Ait Said, H. Nouri, Y. Zebboudj, Eur. Phys. J. Appl. Phys. 67, 30802 (2014).

[8] Y. Zebboudj, G. Hartmann, Eur. Phys. J. Appl. Phys. 7, 167 (1999)

[9] Y. Zebboudj, R. Iken, Eur. Phys. J. Appl. Phys. 10, 211 (2000).

[10] G. Mainelis, A. Adhikari, K. Willeke, S. Lee, T. Reponen, S.A. Grinshpun, J. Aerosol Sci. 33, 1417 (2002).

[11] Q. Lancereau, J.M. Roux, J.L. Achard, J. Aerosol Sci. 63, 146 (2013).

[12] H. Nouri, M. Aissou, H. Ait Said, Y. Zebboudj, Environm. Eng. Manag. J. 16, 2545 (2017).

[13] S.P. Fisenko, W.N. Wang, M. Shimada, K. Okuyama Int. J. Heat Mass Transf. 50, 2333 (2007).

[14] H. Nouri, N. Zouzou, E. Moreau, L. Dascalescu, Y. Zebboudj, J. Electrostat. 70, 20 (2012).

[15] M. Aissou, H. Ait Said, H. Nouri, Y. Zebboudj, J. Electrostat. 76, 108 (2015).
[16] H. Nouri, N. Zouzou, L. Dascalescu, Y. Zebboudj, Process Safety Environm. Protect. 146, 225 (2016).

[17] M. Aissou, H. Ait Said, H. Nouri, Y. Zebboudj, Eur. Phys. J. Appl. Phys. 61, 30803 (2013).

[18] M. Townsend, Electricity in Gases, Oxford University Press, 1915, p. 375.

[19] L.B. Loeb, Electric Coronas - Their Basic Physical Mechanisms, University of California Press, Berkeley 1965.

[20] X. Meng, H. Zhang, J. Zhu, J. Phys. D Appl. Phys. 41, 065209 (2008)

[21] R. Tirumala, Y. Li, D.A. Pohlman, D.B. Go, J. Electrostatic 57, 1 (2010).

[22] P. Cooperman, AIEE Trans. 79, 47 (1960).

[23] P. Cooperman, AIEE Trans. 82, 324 (1963)

[24] G. Cooperman, IEEE Trans. 47, 236 (1981)

[25] G.W. Trichel, Phys. Rev. 54, 1078 (1938).

[26] M. Boutlendj, N.L. Allen, IEEE Trans. Electr. Insulat. 28, 86 (1993).

[27] A. Robled Martinez, J. Electrostat. 29, 101 (1992).

[28] Y. Okuyama, T. Kimura, S. Suzuki, H. Itoh, J. Phys. D Appl. Phys. 45, 195 (2012).

[29] M.F. Frechette, S.I. Kamel, in: Proc. IEEE Int. Symp. on Electrical Insulation, Boston (USA), 1988.

[30] G.F. Leal Ferreira, O.N. Oliveira Jr., J.A. Giacometti, J. Appl. Phys. 59, 30 (1986).

[31] K. Yamada, J. Appl. Phys. 96, 2472 (2004).

[32] B.L. Henson, J. Appl. Phys. 52, 709 (1981).

[33] M. Kaci, H. Ait Said, M. Aissou, H. Nouri, Y. Zebboudj, Braz. J. Phys. 45, 643 (2015). 